\title{
Use of Slurry Infiltrated Fiber Concrete in Reinforced Concrete Corner Connections Subjected to Opening Moments
}

\author{
Mohammed A. Elnono ${ }^{1}$, Hamed M. Salem² ${ }^{2}$ Ahmed M. Farahat ${ }^{3}$ and Ashraf H. Elzanaty ${ }^{3}$
}

Received 31 August 2008, accepted 7 December 2008

\begin{abstract}
The use of Slurry Infiltrated Fiber Concrete (SIFCON) in reinforced concrete corner connections subjected to opening bending moments has been experimentally investigated. An experimental program has been carried out, in which fifteen specimens have been tested; six reinforced concrete joints, one fiber reinforced concrete joint, and eight SIFCON joints. Different reinforcing bars' details and different volumes of fraction of fibers $\left(V_{f}\right)$ have been investigated. It was found that, in all the $\mathrm{RC}$ specimens, the joints failed before reaching the capacity of the connecting members. There was also a significant difference in the different joints' efficiency due to the variety of reinforcement details. The use of SIFCON in the joints increased both the joints capacity and ductility. The enhancement of the joint capacity and ductility could reach as high as $66 \%$ and $173 \%$, respectively. This is attributed to the ability of the high volume of fibers to effectively bridge the cracks and retard the compression failure of the diagonal struts in the joints. The increase in the amount of fibers was proven to directly enhance the behavior of the SIFCON joints. In joints with $V_{f}=6 \%$ and $8 \%$, the joint capacity exceeded the connecting members' capacity, leading to failure in the members before the joints, which is an advantageous requirement of the design.
\end{abstract}

\section{Introduction}

Reinforced concrete corner connections may be subjected to either opening bending moments or closing bending moments. Opening moments are moments that tend to rotate the adjoining members away from each other, causing tensile stresses in the inner side and compressive stresses in the outer side. On the other hand, closing moments are moments that tend to rotate the adjoining members closer to each other, causing tensile stresses in the outer side and compressive stresses in the inner side. The joints should be strong enough that they do not fail before the connecting members, i.e. the desired capacity of the connecting members should be attained without any failure of the joints.

The existing literature shows that early construction detailing was based on past experience. Experimental investigations (Swann 1969; Mayfield et al. 1971; Balint 1972; Nilsson 1973; Salem 1995) have been carried out to investigate the behavior of opening joints. They all agreed that the ultimate strengths of the opening joints were less than those of their adjoining members. A considerable variation of the results for various reinforcement layouts have also been observed among the different authors. Salem (1995) applied the strut-

\footnotetext{
${ }^{1}$ Post graduate student, Structural Engineering Dept., Cairo University, Giza, Egypt.

${ }^{2}$ Associate professor, Structural Engineering Dept., Cairo University, Giza, Egypt.

E-mail:hhadhoud@appliedscienceint.com

${ }^{3}$ Professor, Structural Engineering Dept., Cairo University, Giza, Egypt.
}

and-tie model to the opening joints and proved that the joint strength is always less than the strength of the adjoining members unless additional reinforcement or an anchor plate is used to anchor the main reinforcement outside the joints.

One of the possible approaches to enhance the behavior of those joints is to use fiber reinforced concrete. However, the practical volume fraction of fibers in conventional FRC is within $2 \%$, because premixing fibers more than $2 \%$ by volume may lead to fiber segregation, fiber balling and excessive air entrainment (ACI 2002; Haynes 1968; Lankard and Newell 1984). This volume of fibers will not improve the strength of the concrete in a significant way, though it will increase the toughness of the concrete. In order to obtain an increase in strength, rather than only an increase in toughness, a higher volume of fibers should be used. Slurry Infiltrated Fiber Concrete (SIFCON) is a high-performance fiber reinforced cementitious composite (HPFRCC) in which a high volume fraction of fibers is used. It is made by preplacing a large volume fraction of fibers into the formwork, followed by infiltration of cement-based slurry. SIFCON was first used in 1968 by Haynes. Later, in 1984, Lankard and Newell showed the concept of SIFCON use in the construction of pavement overlays. Later in the 1980s and 1990s, Naaman and his group extensively studied the basic behavior of SIFCON (Homrich and Naaman 1987; Naaman and Homrich 1989; Naaman et al. 1991; Kosa et al. 1991; Hamza and Naaman 1996; Naaman and Najm 1991; Naaman et al. 1992; Naaman and Baccouche 1995; Hota and Naaman 1997; Naaman 2003). The practical range of fiber volume fractions in SIFCON is 4 to $12 \%$. However, volume fractions up to $27 \%$ have been reported in the tech- 
nical literature (Naaman et al. 1991). Due to its high volume of fibers, SIFCON offers superior properties in terms of tension, compression, shear, bond with reinforcing bars, and impact. As illustrated by Naaman (2003) in Fig. 1, for a member under tension, the higher volume of fibers (Fig. 1.b) would lead to multiple cracks that follow the first crack, in an opposite manner to low volume of fibers (Fig. 1.a), which is only accompanied by a single crack. Consequently, an increase in strength takes place in the concrete with higher volume of fibers and this takes place parallel with the cracking process in a way similar to strain hardening. Finally, failure is localized in a single crack and the concrete experiences softening.

Though it is possible to use only cement slurry, the use of very fine sand in slurry enhances the properties of SIFCON. This helps reduce shrinkage cracking and enhances the bond between the fibers and the paste. The benefits of using fine sand might be significant in terms of strength, stiffness and cost. (Naaman et al. 1991). Four main variables affect SIFCON properties: slurry strength, fiber volume $\left(V_{f}\right)$, fiber alignment, and fiber type. The cement slurry is the backbone of the specimen. It affects the elastic modulus, tensile strength, and compression strength of the SIFCON matrix. Fiber pullout strength also depends upon the slurry's compressive strength. The cracking procedure is directly affected by the fiber volume as well as fibers alignment (random, normal to, or parallel to loading). Therefore, both the fiber volume and alignment greatly affect the ultimate strength, residual strength, ductility, and energy absorption. The fiber type was also found to affect the cracking procedure and the elastic modulus of SIFCON (Naaman et al. 1991).

\section{Research significance}

The objective of the current study is to investigate the

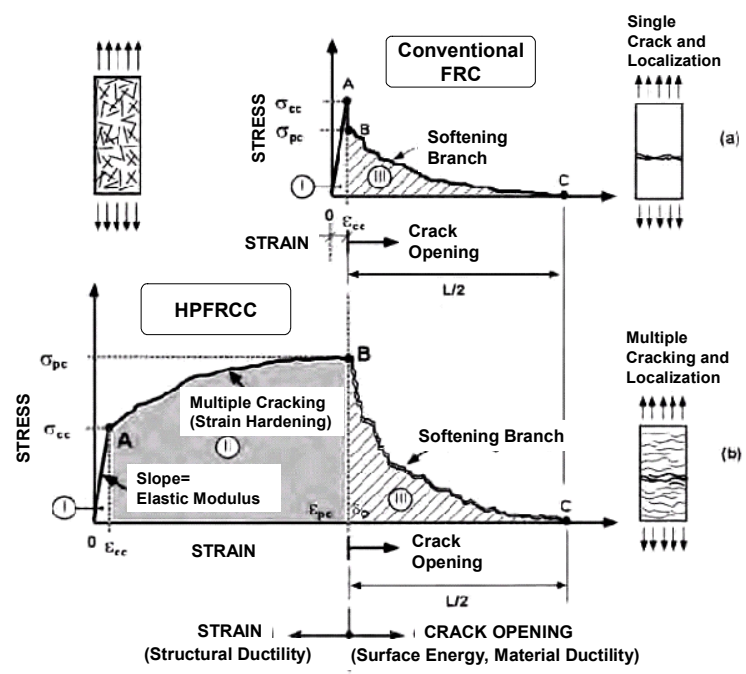

Fig. 1 Behavior of HPFRCC versus conventional FRC (Naaman, 2003). effect of using slurry infiltrated fiber concrete on the behavior of corner connections subjected to opening bending moments. Both the capacity and ductility of joints are investigated for different reinforcement details and different ratio of volume of fibers. The significance of the outcome of this study arises from the increase in the corner joints' ultimate capacity, which is favorable for the framing action, in a way such that the desired capacity of the connecting members could be attained without failure of the joints.

\section{Experimental program}

The experimental program consists of fifteen specimens constituting three groups, as shown in Table 1. The first group consists of six specimens with different arrangement of details of joint reinforcement and is considered as the reference group. The second group includes six specimens similar to those of group I except that the joints are made up of SIFCON with $V_{f}=4.5 \%$. The third group consists of three specimens similar to specimen B6 but with joints not made up of conventional concrete. One joint was made up of FRC with $V_{f}=2 \%$, while the two other joints were made up of SIFCON with $V_{f}=6 \%$ and $8 \%$, respectively. The reason for the use of the same reinforcement details as those of B6, in this group, is that B6 was proven to have the best performance in group I. The fibers used in the specimens of both group 2 and 3 are hooked-ended steel fibers with $50 \mathrm{~mm}$ length.

\subsection{Test specimens}

Each specimen is a U-frame, consisting of three members connected in a way that results in two similar connections as shown in Fig. 2. All specimens have a rectangular section of $150 \times 250 \mathrm{~mm}$. For all specimens, the reinforcement of the two connections is identical. The main (tension) reinforcement is 4D12 and the sec-

Table 1 Test specimens.

\begin{tabular}{|c|c|c|c|c|}
\hline \multicolumn{2}{|c|}{ Specimens } & $\begin{array}{c}V_{f} \\
(\%)\end{array}$ & $\begin{array}{c}\text { Fiber } \\
\text { length } \\
(\mathrm{mm})\end{array}$ & Fiber type \\
\hline \multirow{4}{*}{$\begin{array}{c}\text { Group } \\
\text { I }\end{array}$} & B1 & - & - & - \\
\cline { 2 - 5 } & B2 & - & - & - \\
\cline { 2 - 5 } & B3 & - & - & - \\
\cline { 2 - 5 } & B4 & - & - & - \\
\cline { 2 - 5 } & B5 & - & - & - \\
\cline { 2 - 5 } & B6 & - & - & - \\
\hline \multirow{4}{*}{ Group } & B1F4 & $4.5 \%$ & 50 & Hooked-end \\
\cline { 2 - 5 } & B2F4 & $4.5 \%$ & 50 & Hooked-end \\
\cline { 2 - 5 } & B3F4 & $4.5 \%$ & 50 & Hooked-end \\
\cline { 2 - 5 } & B4F4 & $4.5 \%$ & 50 & Hooked-end \\
\cline { 2 - 5 } & B5F4 & $4.5 \%$ & 50 & Hooked-end \\
\cline { 2 - 5 } & B6F4 & $4.5 \%$ & 50 & Hooked-end \\
\hline \multirow{4}{*}{$\begin{array}{c}\text { Group } \\
\text { III }\end{array}$} & B6F2 & $2.0 \%$ & 50 & Hooked-end \\
\cline { 2 - 5 } & B6F6 & $6.0 \%$ & 50 & Hooked-end \\
\cline { 2 - 5 } & B6F8 & $8.0 \%$ & 50 & Hooked-end \\
\hline
\end{tabular}



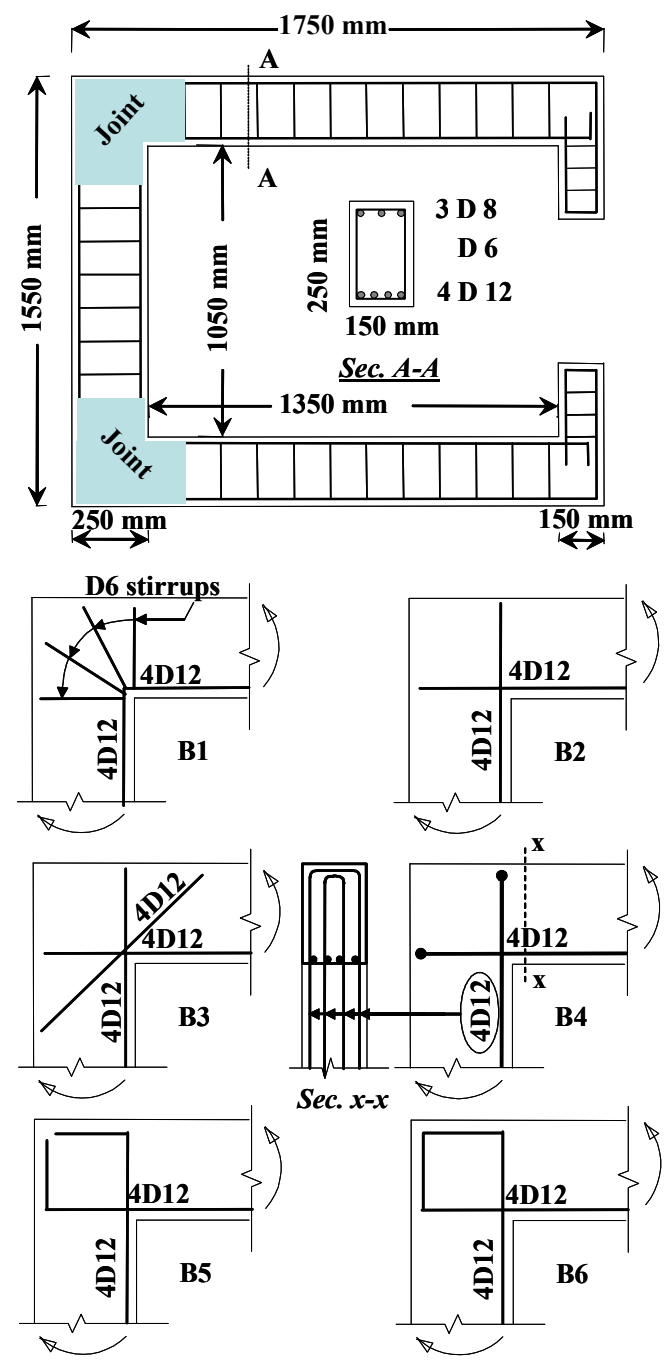

Sec. $x-x$

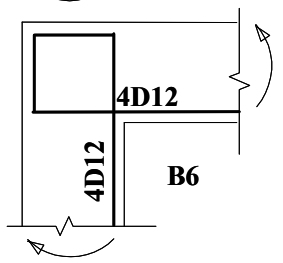

Fig. 2 Details of test specimens.

ondary (compression) reinforcement is 3D8. D6 stirrups, consisting of two branches, are used with $120 \mathrm{~mm}$ spacing.

In specimens $\mathrm{B} 1$ and $\mathrm{B} 1 \mathrm{~F} 4$, the tension reinforcements are directly connected and diagonal stirrups are used in the joint region, while for the rest of the specimens, the tension reinforcements are passed to the joint outer face with different end details as shown in Fig. 2. In specimens B3 and B3F4, additional 4D12 diagonal bars are used in the joint region, while in specimens B4 and B4F4, the tension reinforcement is hair-pinned as shown in Fig. 2.

\subsection{Material properties}

Deformed bars of $12 \mathrm{~mm}$ diameter were used for the main reinforcement while plain bars of 8 and $6 \mathrm{~mm}$ diameters were used for the secondary reinforcement and stirrups, respectively. Minimum yield stress of $458 \mathrm{MPa}$ and $240 \mathrm{MPa}$ and elongation of $12 \%$ and $20 \%$ were recorded for deformed and plain bars, respectively. The mixes used for both concrete and SIFCON were developed through trial batching and were designed to develop concrete and SIFCON compressive strength of 40 $\mathrm{MPa}$ at the age of 28 days. The concrete mix consisted of ordinary Portland cement, natural sand, coarse gravel (crushed dolomite), and water. The proportions of the used concrete mix are given in Table 2. The mix used for the SIFCON consisted of cement, natural sand and water. A water-reducing admixture (super-plasticizer) was added to the mix to increase the workability and the ability to infiltrate the fiber matrix without increasing the water content. The proportions of the used mix are given in Table 2.

The average recorded compressive strength for standard cubes of concrete and SIFCON was $40.5 \mathrm{MPa}$ and 41.3 $\mathrm{MPa}$, respectively. The average recorded elastic modulus was $3100 \mathrm{MPa}$ and $3110 \mathrm{MPa}$ for concrete and SIFCON, respectively.

\subsection{Preparation of test specimens}

The test specimens were cast in wood formworks in a horizontal position to facilitate concrete placement and to prevent any possible cavities or air pockets during casting. As shown in Fig. 3, thin steel nets separating the conventional concrete zone and the SFCON zone were used in order to keep the conventional concrete from infiltrating into the SIFCON zone. At first, concrete was cast in the whole specimen except the two joints. After that, SIFCON was cast in the joint zone in five layers. In each layer, random fibers were placed by hand, and then slurry was infiltrated through the fibers until they were covered, as shown in Fig. 4. It is obvious here that the fiber placement and the casting direction of the specimens are perpendicular to that in the real structures. However, the authors believe that this will not be significant as the fibers are placed in a random way in several layers with a homogenous slurry infiltration. After 24 hours, the sides of the form were removed. The beams were cured by water for about 10 days, and tested after 28 days. Three standard cubes were cast using the same mix, in order to determine the compressive strength of the mix. These cubes were kept under the same environmental conditions as the tested beams until the day of testing.

Table 2 Proportions of concrete and SIFCON mixes.

\begin{tabular}{|l|c|c|}
\hline \multirow{2}{*}{\multicolumn{1}{|c|}{ Item }} & \multicolumn{2}{c|}{ Weight $\left(\mathrm{Kg} / \mathrm{m}^{3}\right)$} \\
\cline { 2 - 3 } & Concrete & SIFCON \\
\hline Portland cement & 400 & 900 \\
\hline Natural sand & 600 & 900 \\
\hline Coarse gravel & 1130 & --- \\
\hline Water & 200 & 360 \\
\hline Super-plasticizer & --- & 11.5 \\
\hline $\begin{array}{l}\text { 28 days compres- } \\
\text { sive strength } \\
(\mathrm{MPa})\end{array}$ & 40.5 & 41.3 \\
\hline
\end{tabular}




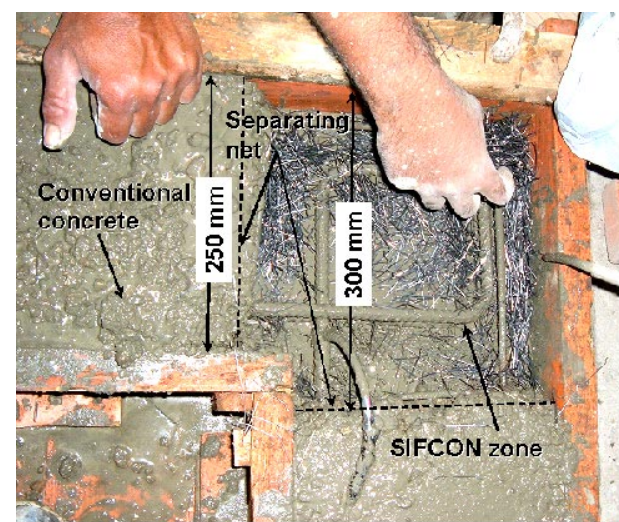

Fig. 3 Placement of fibers in joint zone.

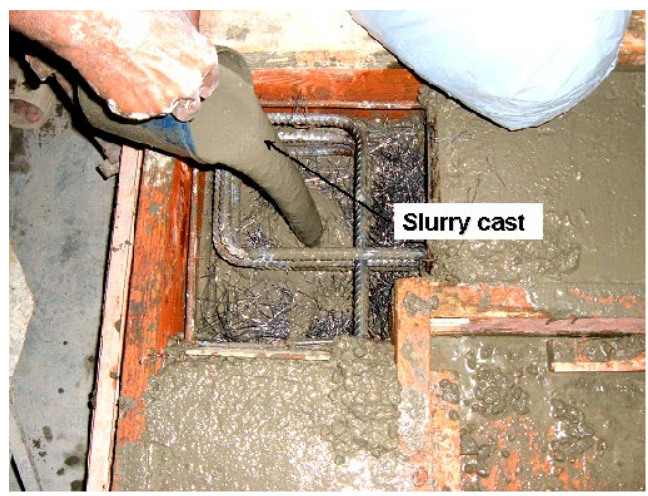

Fig. 4 Slurry infiltration into fiber matrix.

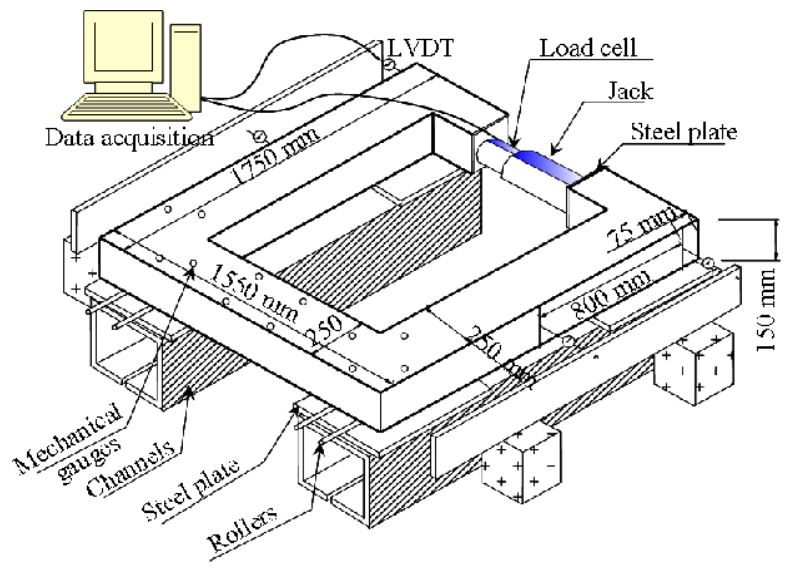

Fig. 5 Test setup and instrumentation.

\subsection{Test setup and instrumentation}

The test specimens were placed horizontally as shown in Fig. 5. The test specimens were loaded using a 100 $\mathrm{kN}$ capacity hydraulic jack driven by a manual pump. The jack was placed between the ends of the cantilevers pushing against two stubs. Such loading caused the cantilevers to move away from each other and the joints to be opened. Two $25 \mathrm{~mm}$ diameter steel pipes were placed under each cantilever to allow the horizontal movement of the cantilevers, eliminating possible friction of the cantilevers with the steel beams underneath the specimens.

The rate of load application was $1.0 \mathrm{kN} / \mathrm{min}$ until failure. A $100 \mathrm{kN}$ capacity load cell was placed between the jack and the cantilever stub to monitor the load increment. Four Linear Variable Differential Transducers (LVDTs) of 0.001-mm sensitivity were used to measure the deflections of the cantilevers. They were attached to the ends as well as the mid span of the outer side of cantilevers, as shown in Fig. 5. It should be mentioned that the deflection of each individual cantilever could not be recorded separately since the specimen might have a rigid body motion. However, the summation of the deflections of the two cantilevers shows a good representation of the specimen behavior.

For each connection, the average strain in a direction perpendicular to the joint diagonal was measured in two locations using two mechanical gauges spaced at 200 $\mathrm{mm}$. From those strains, the average rotation of the connection could be obtained. In addition, the propagation of cracks at each load increment was observed. An Ultra Lens instrument with accuracy of $0.1 \mathrm{~mm}$ was used to measure the crack width. Electrical strain gauges were fixed to the main reinforcement at locations of maximum tension to record the steel strains at these locations.

A computer-controlled data acquisition system was used to collect the load, deflections and strains at fixed intervals. The test was terminated when the tested beam was fractured or when extensive deformation was observed.

\section{Experimental results and discussion}

The efficiency of the joint is defined as the joint capacity divided by the connecting members' capacity. Since in the opening joints, the joint capacity is expected to be less than the members' capacity, the failure of the joint precedes the failure of the member and the efficiency is less than $100 \%$. In this study, the capacity of the joint is experimentally recorded while the member capacity is calculated using the beam theory since it is not attainable in the experiment.

\subsection{Cracking pattern and failure mode}

In both specimens B1 and B1F4, cracks initiated in the inner side of the joints and propagated towards the outer side at the borders of the joints as shown in Fig. 6 (a and b). As a result of directly connecting the tensile reinforcement of the connecting members, resultant diagonal tensile stresses developed in the joint and led to inner concrete cover spalling parallel to the tension reinforcement. The inability of the diagonal stirrups to resist the resultant diagonal forces led to the widening of those cracks, which eventually led to the failure of the joint, with the load dropping and the joint failing before the connecting members. The cracking pattern for the rest of specimens was different from B1 and 


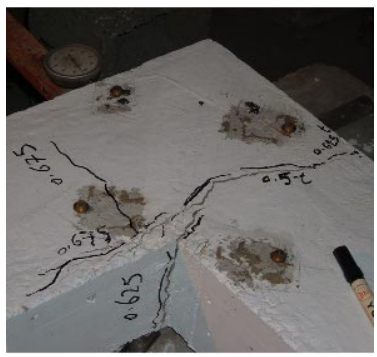

(a) B1

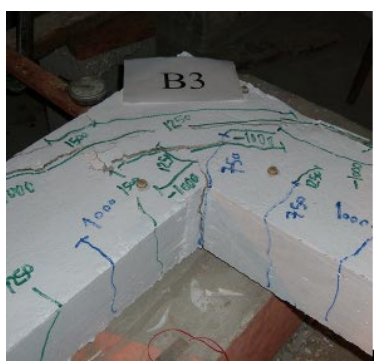

(e) B3

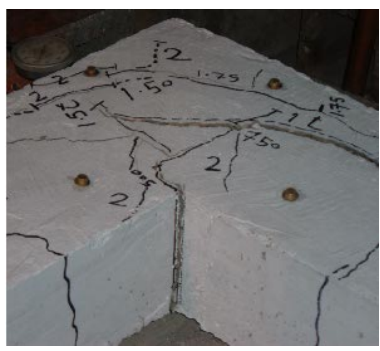

(i) B5

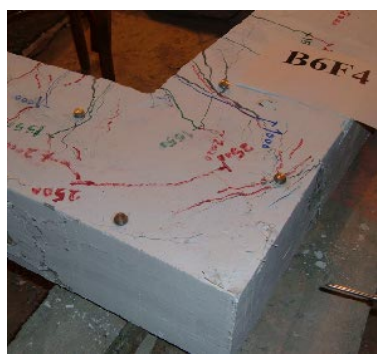

(m) B6F4

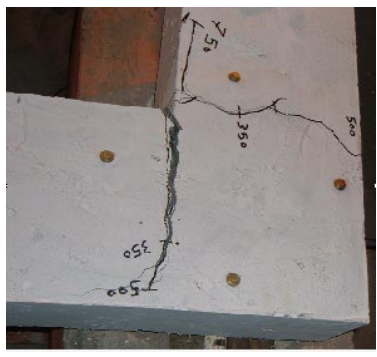

(b) B1F4

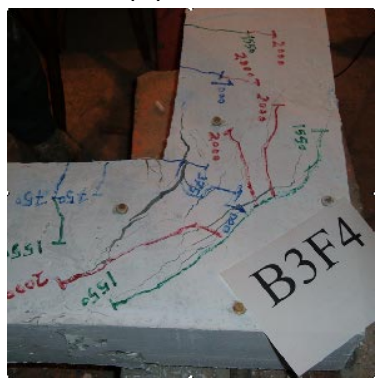

(f) B3F4

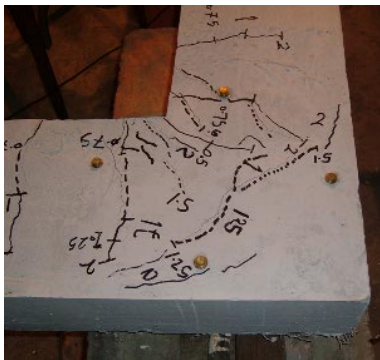

(j) B5F4

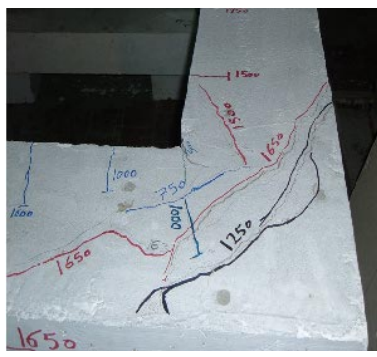

(c) B2

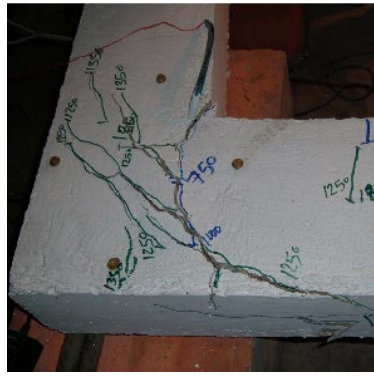

(g) B4

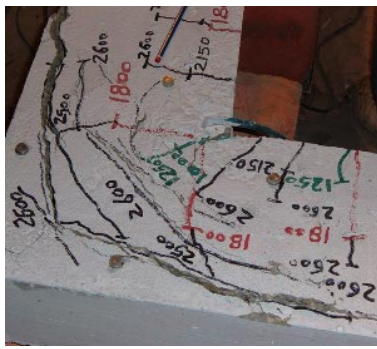

(k) B6

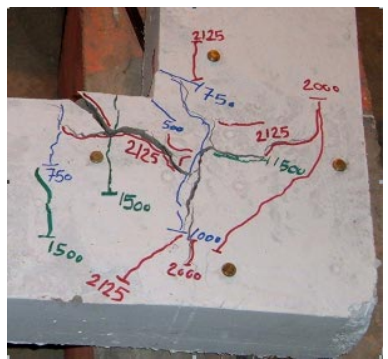

(d) B2F4

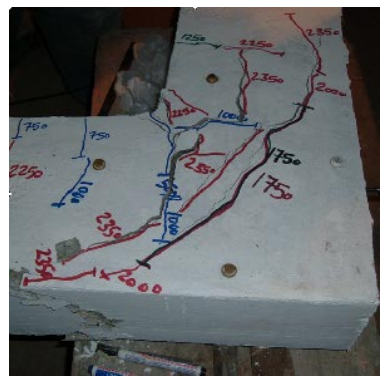

(h) B4F4

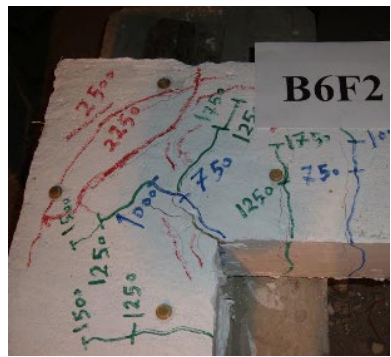

(I) B6F2

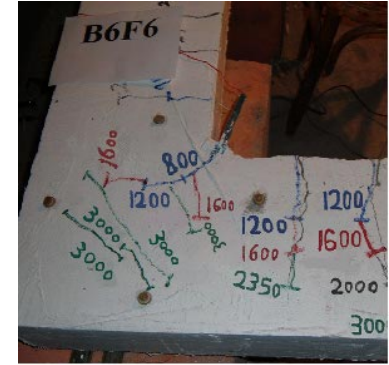

(n) B6F6

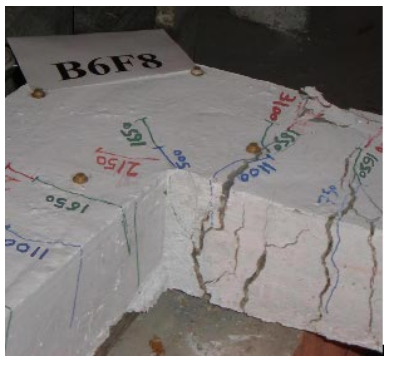

(o) B6F8

Fig. 6 Cracking pattern of specimens.

B1F4. Cracks initiated in the inner corner and propagated diagonally to the outer corner of the joint. With loading increases, diagonal cracks, perpendicular to the initial ones, developed in the joint as shown in Fig. 6 (c through n). These diagonal cracks eventually widened, leading to compression failure of the diagonal struts. Multiple cracks with smaller crack widths were generally observed in the SIFCON joints as clearly observable in Fig. 6. This means that the fibers could effectively bridge the cracks and enhance crack distribution. In specimen $\mathrm{B} 6 \mathrm{~F} 8$, the one with the largest $V_{f}$ value, diagonal cracks were not visible and failure took place in one of the connecting members, as shown in Fig. 6(o).

\subsection{Results for groups I and II}

Figure 7 shows the load-deflection relation for specimens of groups I and II. The deflection represents the average deflection of the two cantilevers of each specimen. The performance of each specimen is evaluated with two main records, the ultimate capacity and the strain energy, as illustrated in Figs. 8 and 9, respectively. Since the behavior of the majority of joints was brittle (failure took place in the joints before yielding of the main reinforcement of the adjoining members), the ductility of the joints was measured by their strain energy, which was arbitrarily calculated up to the peak point, just prior to strength degradation. 

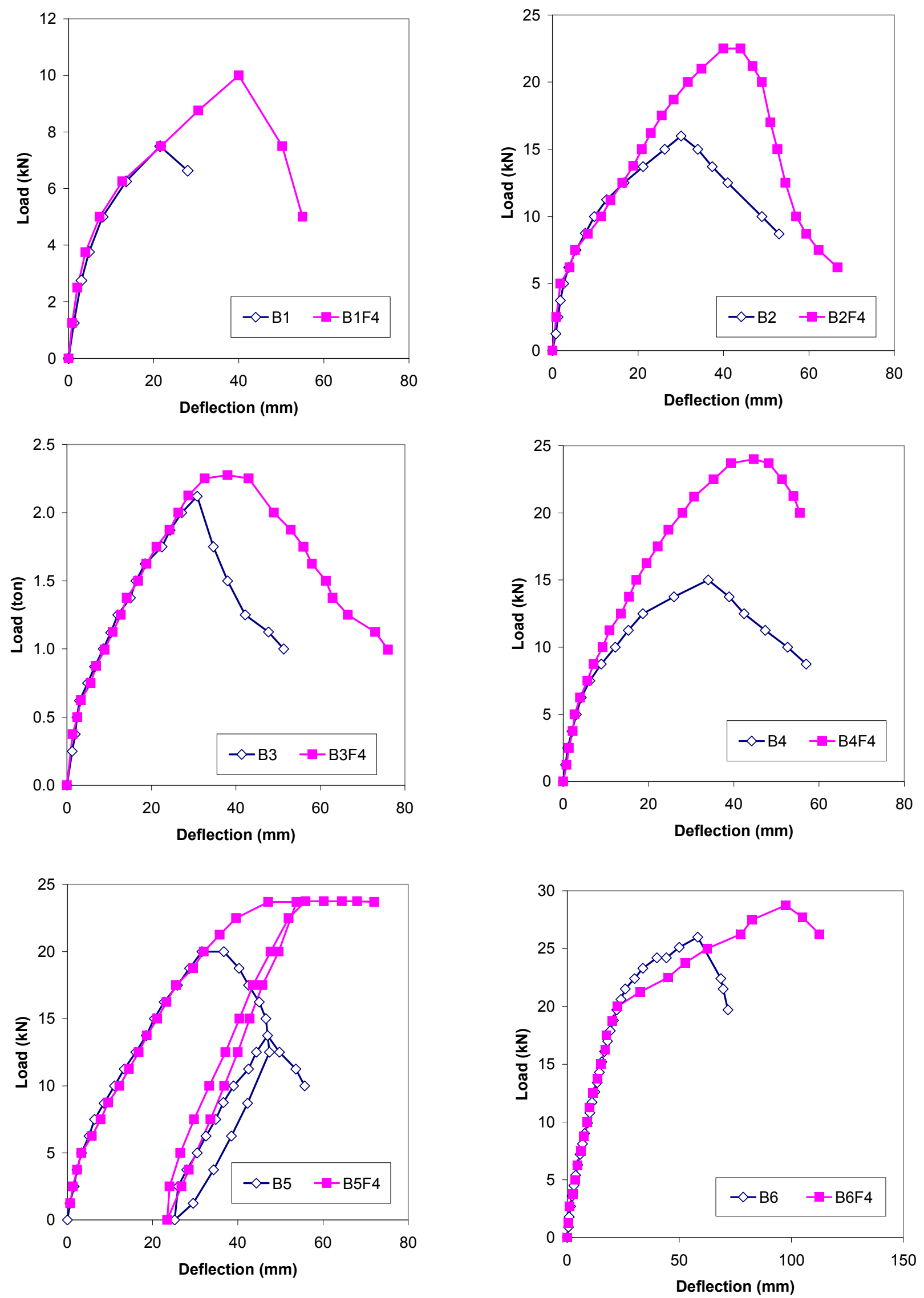

Fig. 7 Load-deflection relations for group I (conventional RC joints) and group II (SIFCON joints). 


\subsubsection{Effect of reinforcement details}

For the conventional RC joints, all specimens failed in a brittle manner with a joint efficiency of less than $100 \%$. In other words, the joints failed before reaching the ultimate capacity of the connecting members. The results show a significant difference in joint efficiency, reaching as high as $63 \%$, due to the variety of reinforcement details. Among the specimens, B1 and B6 showed the worst and the best performance with joint efficiencies of $26 \%$ and $89 \%$, and strain energy of $110 \mathrm{kN}$.mm and 1106 kN.mm, respectively. The least damage was observed in joint B6. The rotation observed for the joints of B6 was the least, as shown in Fig. 10.

\subsubsection{SIFCON versus conventional RC}

Figure 7 shows the load-deflection relations for SIFCON joints compared to those of conventional reinforced concrete joints. In general, the behavior of the SIFCON joints is superior to that of the conventional RC joints. The SIFCON joints had a higher joint capacity and a better ductility. Figure 8, which compares the efficiency of the joints of both group I and group II, shows that an efficiency enhancement ranging from $5.9 \%(\mathrm{~B} 3 \mathrm{~F} 4)$ to $66.7 \%$ (B4F4) could be obtained for the SIFCON joints compared to the RC joints. Figure 9 shows the strain energy in the joints of both group I and group II, where it can be seen that an energy-absorption enhancement that ranges from $39 \%$ (B3F4) to $160 \%$ (B5F4) could be obtained for the SIFCON joints compared to the RC joints.

The fibers could effectively bridge the cracks in the SIFCON specimens, reduced the crack width, and enhanced the crack distribution. This in turn retarded the failure of the diagonal strut in the joint and thus increased the strength and the ductility of the joint. Unlike the SIFCON joints, the RC joints eventually developed wide diagonal cracks and in some cases spalling of the concrete (e.g. B3, B4 and B6). The bridging effect of the fibers was reflected in the rotation of the SIFCON joints, where they experienced less rotation than the conventional RC joints, as shown in Fig. 10.

\subsection{Results for group III (effect of $V_{f}$ )}

Regarding the third group, the effect of the volume of fibers on the behavior of the SIFCON joints is discussed. As shown in Fig. 11, a significant enhancement of the behavior of the joint is clearly observed with the increase of $V_{f}$. Both the efficiency and the ductility of the SIFCON joints increased with the increase of $V_{f}$ as shown in Figs. 12 and 13. The increase in the efficiency, compared to the RC joint, ranged from $1.85 \%$ for $\mathrm{B} 6 \mathrm{~F} 2$ $\left(V_{f}=2 \%\right)$ to $20 \%$ for B6F8 $\left(V_{f}=8 \%\right)$, while the energyabsorption enhancement ranged from $37 \%$ for B6F2 $\left(V_{f}\right.$ $=2 \%)$ to $173 \%$ for $\mathrm{B} 6 \mathrm{~F} 8\left(V_{f}=8 \%\right)$.

From the experimental results of group III, the following numerical relations could be obtained for both the joint efficiency, $\eta(\%)$, and the strain energy, $E$ (kN.mm), as a function of the volume of fraction of fi-

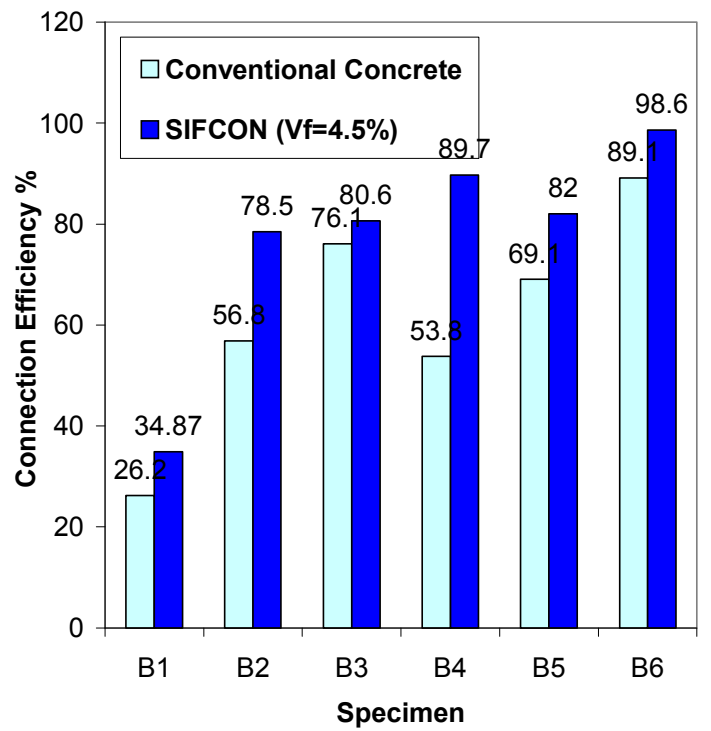

Fig. 8 Efficiency of joints of groups I and II.

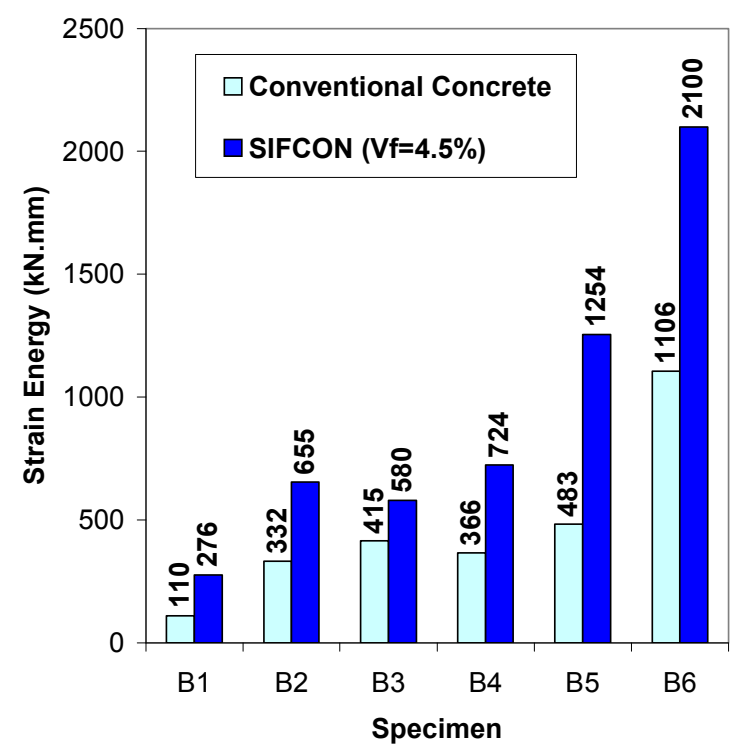

Fig. 9 Strain energy in joints of groups I and II.
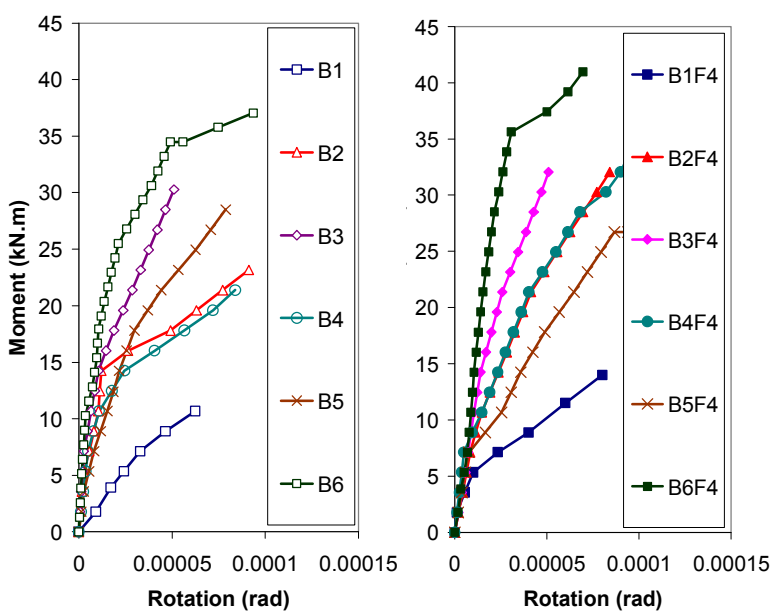

Fig. 10 Moment-rotation relation for groups I and II. 
bers, $V_{f}(\%)$ :

$$
\begin{aligned}
& \eta=\eta_{0}+2.45 V_{f} \\
& E=E_{0}+241 V_{f}
\end{aligned}
$$

where $\eta_{0}$ and $E_{0}$ are the efficiency and the energy for the conventional concrete with no fibers, respectively.

The higher the volume of fraction of fibers, the higher the ability of crack bridging is. With the increase of $V_{f}$, the crack width decreased, retarding the widening of the diagonal cracks and hence the failure of the diagonal strut in the joint, and thus increasing both the strength and the ductility of the joint. In joints B6F6 and B6F8, the joint capacity exceeded the connecting member capacity, leading to failure in the member before the joint. This is quite obvious particularly for $\mathrm{B} 6 \mathrm{~F} 8$ as shown in Fig. 6(o), where the diagonal cracks were not visible

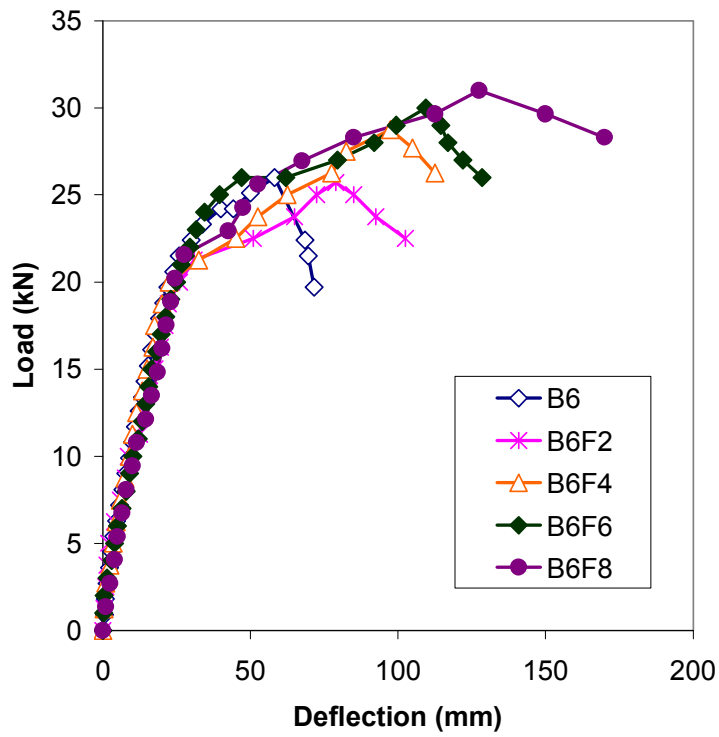

Fig. 11 Load-deflection relations for group III.

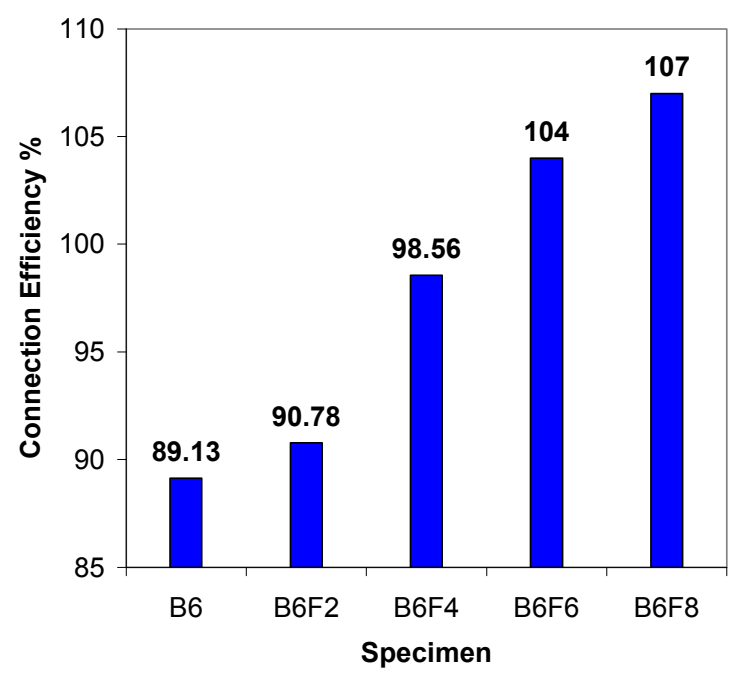

Fig. 12 Efficiency of joints of group III.

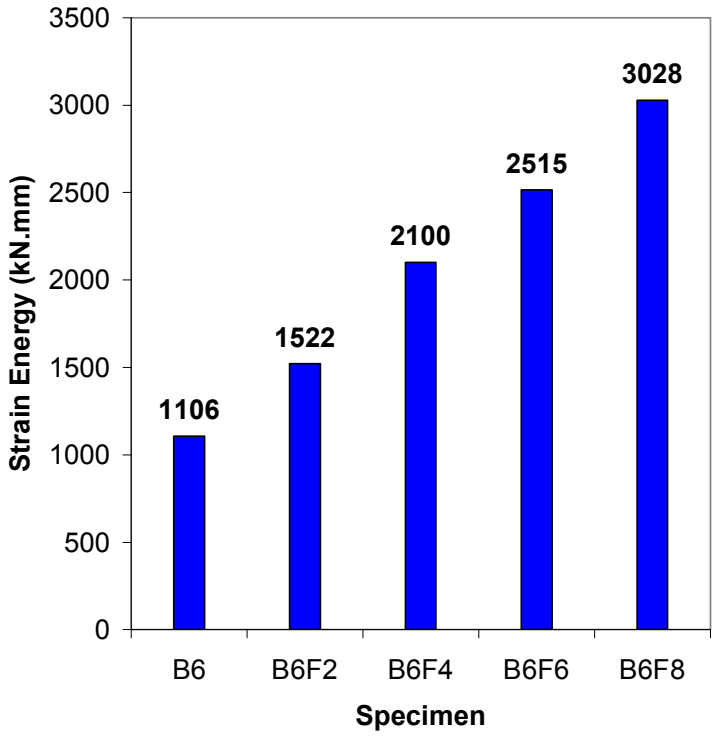

Fig. 13 Strain energy in joints of group III.

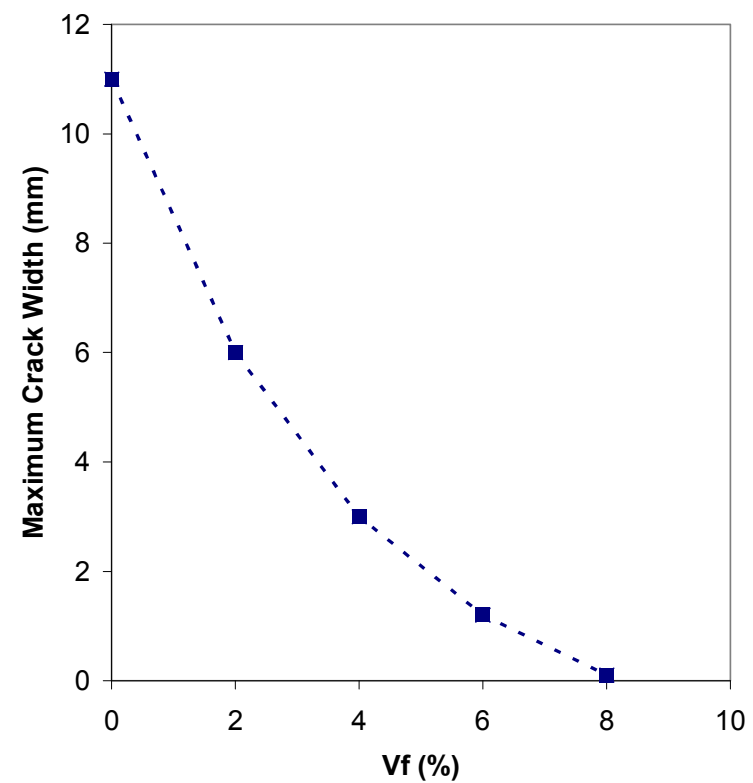

Fig. 14 Maximum observed crack width in joints for Group III.

and failure took place in one of the connecting members.

The maximum recorded crack widths in the joints of Group III are shown in Fig. 14, where the effect of the amount of $V_{f}$ is clear. The following equation is obtained by curve fitting for the maximum crack width $(\mathrm{mm})$ as a function of $V_{f}(\%)$ :

$$
w=10.8-2.62 V_{f}+0.16 V_{f}^{2}
$$

\section{Conclusions}

From the experimental results of the current study, the following conclusions can be drawn. 
- In all the RC specimens, the joint failed before reaching the capacity of the adjoining members. There was a significant difference in the joints' efficiency due to the variety of reinforcement details. The difference between the lowest and highest efficiencies reached $63 \%$.

- The worst behavior obtained was that for B1, where the tension reinforcement of the two connecting members is directly connected together, while the best behavior was that for B6, where the tension reinforcement is connected in a tie shape.

- The use of SIFCON in the joints increased both the joints' efficiency and ductility. The enhancement of the joint efficiency and ductility reached as high as $66 \%$ and $173 \%$, respectively. This is attributed to the ability of the high volume of fibers to effectively bridge the cracks and enhance the cracking pattern, which eventually led to retarding the compression failure of the diagonal struts and increasing both strength and ductility.

- The increase in the amount of fibers in SIFCON was proven to proportionally enhance the behavior of the SIFCON joints. In joints with $V_{f}=6 \%$ and $8 \%$, the joint capacity exceeded the connecting member capacity, leading to failure in the member before the joint. The crack width decreased with increases in $V_{f}$. No visible cracks were observed in the joints with $V_{f}=8 \%$. It should be mentioned also that no cover spalling was observed in the SIFCON concrete joints.

\section{References}

ACI 544.1R-96 (2002). "State-of-the-art report on fiber reinforced concrete."

Balint, P. S. and Taylor H. P. J. (1972). "Reinforcement detailing of frame corner joints with particular reference to opening joints." Cement and Concrete Association Technical Report No. 42.462, London.

Hamza, A. M. and Naaman, A. E. (1996). "Bond characteristics of deformed Reinforcing Steel Bars Embedded in SIFCON." ACI Materials Journal, 93(6), 578-588.

Haynes, H. H. (1968). "Investigation of fiber reinforcement methods for thin shell concrete." Naval Civil Engineering Laboratory, Port Hueneme, CA, N979, 1-26. [adopted from Lankard and Newell, 1984]

Homrich, J. R. and Naaman, A. E. (1987). "Stress-strain properties of SIFCON in compression." Fiber Reinforced Concrete - Properties and Applications.
ACI SP-105, American Concrete Institute, Detroit, Michigan, 283-304.

Hota, S. and Naaman, A. E. (1997). "Bond stress-slip response of reinforcing bars embedded in SIFCON under cyclic loading." ACI Structural Journal, 94(5), 525-537.

Kosa, K., Naaman, A. E. and Hansen, W. (1991). "Durability of fiber reinforced mortar." ACI Material Journal, 88(3), 310-319.

Lankard, D. R. and Newell, J. K. (1984). "Preparation of highly reinforced steel fiber reinforced concrete composites." Fiber Reinforced Concrete International Symposium, ACI SP-81, American Concrete Institute, Detroit, 287-306.

Mayfield. B., Kong. F.-K., Bennison. A. and Twiston Davis, J. C. D. (1971). "Corner joint details in structural lightweight concrete." ACI Journal, 68(5), 366-372.

Naaman, A. E. and Homrich, J. R. (1989). "Tensile stress-strain properties of SIFCON." ACI Materials Journal, 86(3), 244-251.

Naaman, A. E., Otter, D. and Najm, H. S. (1991). "Elastic modulus of SIFCON in tension and compression." ACI Materials Journal, 88(6), 603-612.

Naaman, A. E. and Najm, H. S. (1991). "Bond-slip mechanisms of steel fibers in concrete." $A C I$ Materials Journal, 88(2), 135-145.

Naaman, A. E., Reinhardt, H. W. and Fritz, C. (1992). "Reinforced concrete beams with a SIFCON matrix." ACI Structural Journal, 89(1), 79-88.

Naaman, A. E. and Baccouche, M. R. (1995). "Shear response of dowel reinforced SIFCON." $A C I$ Structural Journal, 92(3), 587-596.

Naaman, A. E. (2003). "Engineered steel fibers with optimal properties for reinforcement of cement composites." Journal of Advanced Concrete Technology, 1(3), 241-252.

Nilsson, L. O. (1973). "Reinforced concrete corners and joints subjected to bending moments." The National Swedish Institute for Building Research, Box 27163, S-102-52, Stockholm 28, Sweden.

Salem, H. M. (1995). "Application of equilibrium strutand-tie model to reinforced concrete corner connections subjected to opening moments." Master Thesis, Structural Engineering, Cairo University.

Swann. R. A. (1969). "Flexural strength of reinforced concrete portal frames." Cement and Concrete Association Technical Report No. TRA434, London. 